\title{
The Role of Youtubers on Covid-19 Prevention Products' Purchase Intention in the New Normal Era
}

\author{
Prita Ayu Kusumawardhany ${ }^{1 *}$ \\ ${ }^{1}$ University of Surabaya, Surabaya, Indonesia \\ ${ }^{*}$ Corresponding author. Email: pritaayu@staff.ubaya.ac.id
}

\begin{abstract}
Everyone must own personal protective equipment to prevent the Covid-19 transmission. Consumers can buy Covid-19 prevention products at low to high prices. This study examines how YouTube video (vlog) affects millennial consumer perceptions and intention in purchasing Covid-19 prevention products. The social attractiveness, attitude homophily, and the physical attractiveness of the Para-Social Interaction theory (PSI) are used to assess the effect on perceptions of brand awareness, brand-user-imagery fit, brand value, and brand purchase intention. This research has 150 millennial respondents with processing method uses Partial Least Squares Structural equation modeling (PLS-SEM). The results of this study support the proposed model. The use of vlogs by Indonesian YouTubers and PSI as a brand management tool influences millennial consumer intention to determine the purchase of Covid-19 prevention product brands.

Keywords: YouTuber, Para-social Interaction, Brand Management Tool, Purchase Intention, Millennials' Perception.
\end{abstract}

\section{INTRODUCTION}

\subsection{Background}

The first case of Covid-19 in Indonesia was announced in March 2020 by President Joko Widodo. Since then, the government continues to take preventive and optimal handling measures so that the virus does not spread and cause casualties. Various policies have been taken to block the rate of virus transmission, such as the application of physical distancing, Large-Scale Social Restrictions (PSBB), Enforcement of Micro-scale Restrictions on Community Activities (PPKM), and prohibition of homecoming during Ramadan.

Everyone must own personal protective equipment to protect its users from certain health hazards or disorders. Health protocols are strictly enforced to prevent viruses from entering the body through the mouth, nose, eyes, or skin. Covid-19 prevention products are health protection equipment consisting of masks, face shields, gloves, hand sanitizers, wet wipes, vitamins, healthy food, and others highly suggested. Various masks, hand sanitizers, vitamins, healthy foods and drinks, and other prevention products were circulated in the market during the pandemic. They are marketed from low to high prices depending on the product quality and the brand name.

Millennials are a segment of society with high demands for activity even during the pandemic. Therefore, they also need to be aware of the importance of using health protection equipment. YouTube has been named the most popular social media for the Indonesian people. Based on $2021 \mathrm{WeAreSocial}$ and Hootsuite data, YouTube users in Indonesia reach $93.8 \%$ of the total Indonesian internet users aged 16 to 64 years with duration of use of 25.9 hours per month.

This study supports the use of YouTube for developing a relationship through video sharing. YouTube allows users to create and upload videos viewed and shared by hundreds of millions of viewers (Freeman \& Chapman 
2007). The relationship can be created between YouTuber (YouTube vloggers) and viewers as customers through content video sharing.

According to Lee \& Watkins (2016), consumers see themselves as having the same beliefs as YouTubers when watching YouTube vlogs and reviewing a brand. This shows that YouTubers can influence consumer perceptions of a brand. Brand managers must consider the effectiveness of the brand spokesperson and need to find common ground with the personalities of the target market. Dehghani et al. (2016) conclude that brand awareness through YouTube is positively affecting customer purchase. The one-way relationship between YouTuber as a media personality and customer has the potential to influence millennials, especially those aged 16-40-year-old in purchasing Covid-19 products. Reviews provided by YouTubers through vlogs will help millennials grow their interest in always being aware of health protection equipment and help them to choose one of many Covid19 product brands available on the market.

\subsection{Purpose of The Study}

This research aims to examine the influence of YouTubers para-social interactions on brand awareness, brand user imagery fit, brand value, and brand purchase intention from millennials' perceptions.

\subsection{Para-Social Interaction (PSI)}

Labrecque (2014) defines Para-Social Interaction (PSI) as an illusionary experience, such that consumers interact with personas (i.e., mediated representations of presenters, celebrities, or characters) as if they are present and engaged in a reciprocal relationship. Social media such as YouTube can potentially allow two-way communication and a more balanced relationship between media personalities and media users. YouTube enables fans to access the personal life of the media personality; the personality still controls reciprocation in the relationship (Stever \& Lawson 2013). Characteristics of PSI resemble interpersonal friend- ships - they are voluntary, provide companionship, and social attractiveness is a factor in establishing relationships (Ballantine \& Martin 2005).

The more a person sees themselves as similar to others, the more likely they frequently interact. Through these interactions with others, one can confirm their own beliefs. Homophily is defined as the degree to which people who interact are similar in beliefs, education, social status, and the like (Eyal \& Rubin 2003). Frederick et al. (2012) indicate that attraction, attitude homophily, time spent with the medium, and perceived realism are significantly correlated with PSI. Since this study examines the influence of YouTubers, the attractiveness variables (physical and social attractiveness) and attitude homophily are proposed to have a positive influence on PSI. H1. Attitude Homophily and Social Attractiveness (AHSA) have a positive influence on PSI.

H2. Physical Attractiveness (PA) has a positive influence on PSI.

\subsection{Effects of PSI on Consumer's Brand Per- ception}

This study uses brand awareness, brand value, and brand-user imagery fit to measure consumers' perceptions. Social media can build and raise brand awareness since many people are already visiting social media that spread a brand name all over those networks to help notify people about it (Stephen \& Toubia 2010). Since many people are already visiting social media, a brand name spread all over those networks can help notify people about it and become familiar with the firm, creating brand awareness (Dehghani et al. 2016). According to Miller \& Mills (2012), the branduser-imagery fit is the overall assessment of the compatibility or match between themselves and the brand users. Brand value is the overall evaluation of the worth of a brand. 


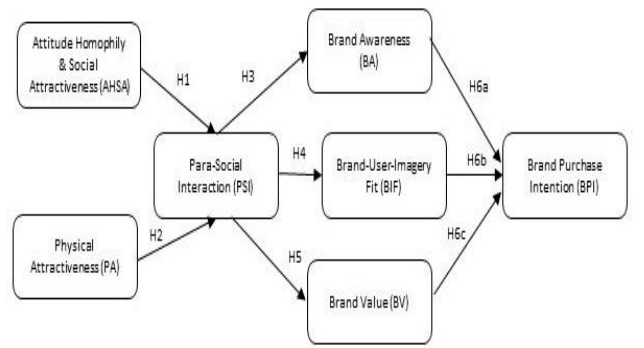

Figure 1. Research Model

Labrecque (2014) reveals that PSI enhances feelings of connectedness with brands, resulting in increased brand loyalty and willingness to share personal information. In this study, YouTubers, acting as brand ambassadors, can elicit positive outcomes for the brands, including increased value and branduser imagery fit. The literature consistently shows that positive brand attitudes and perceptions increase consumer purchase intentions (Bian \& Forsythe 2012, Kim \& Ko 2012, Zhang \& Kim 2013). Therefore, YouTube viewers will be aware of a brand and feel a higher brand value after watching a vlog, which increases the desire to buy the product.

H3. PSI has a positive influence on Brand Awareness (BA).

H4. PSI has a positive influence on Branduser-Imagery Fit (BIF).

H5. PSI has a positive influence on Brand Value (BV).

H6. Brand awareness, brand-user-imagery fit, and brand value have a positive influence on brand purchase intention (BPI).

\section{RESEARCH METHODS}

This study uses 150 millennial respondents, contacted via online surveys. The characteristics of respondents were the millennial generation who access YouTube everyday, aged 16-40 years, and living in Indonesia. Millennial respondents were asked to provide their perception of the YouTuber and Covid-19 products. This research uses purposive sampling as a non-probability sampling technique.

The instrument used in this study was questionnaires. Attitude Homophily/Social
Attractiveness (AH/SA), Physical Attractiveness (PA), PSI, Brand Awareness (BA), brand-user-imagery fit (BIF), brand value (BV), and Brand Purchase Intentions (BPI) were measured using five (5) point Likertscale. Data from questionnaires were processed and analyzed using Partial Least Squares Structural Equation Modeling (PLSSEM) using Smart PLS 3.0, and the proposed hypotheses were tested through path coefficients analysis.

\section{RESULTS AND DISCUSSIONS}

Of 150 respondents, $60 \%$ were females and $40 \%$ were males. All respondents met the criteria for the millennial generation with 67 participants were aged $15-20$ years $(45 \%), 60$ participants were aged $21-25$ years $(40 \%)$, 17 participants were aged $26-30$ years $(11 \%)$, and 6 participants were aged $31-40$ years $(4 \%)$.

The majority of respondents were students, but some had graduated and worked as employees or entrepreneurs. Respondents in this study varied from various backgrounds with shopping expenses from below 1 million to more than 5 million rupiahs. While, $50 \%$ of respondents have shopping expenses of 1 to 3 million rupiahs per month. As the respondents defined in this study were millennials, who watch YouTube everyday, from the distribution of the questionnaire, it can be found that 72 respondents like the content of lifestyle product reviews, and 78 respondents like the content of food and beverage products. Lifestyle products include masks, face shields, gloves, and fashion that could support the users' appearance during the pandemic but still meet health protocols. Meanwhile, culinary products include food, drinks, and vitamins that could boost immunity during the pandemic. Respondents watch the product reviews through YouTube videos shared by their favorite Indonesian YouTubers. The frequently mentioned YouTubers are Raditya Dika, Deddy Corbuzier, Jang Hansol, Arief Muhammad, Baim Wong, and many more. 
$\underline{\text { Table 1. Respondents Profile }}$

\begin{tabular}{|c|c|c|}
\hline Variable & Item & Percentage (\%) \\
\hline \multirow[t]{2}{*}{ Gender } & Male & 40 \\
\hline & Female & 60 \\
\hline \multirow[t]{4}{*}{ Age } & $15-20$ & 26 \\
\hline & $21-25$ & 40 \\
\hline & $26-30$ & 11 \\
\hline & $31-40$ & 4 \\
\hline \multirow[t]{4}{*}{ Education } & High School Graduate & 30 \\
\hline & Bachelor Degree & 68 \\
\hline & Master & 2 \\
\hline & Degree & \\
\hline \multirow[t]{3}{*}{ Profession } & Student & 89 \\
\hline & Enterpreneur & 5 \\
\hline & Employee & 6 \\
\hline \multirow{4}{*}{$\begin{array}{l}\text { Expenses per } \\
\text { month (IDR) }\end{array}$} & Less than $1,000,000$ & 20 \\
\hline & $1,000,000-3,000,000$ & 50 \\
\hline & $3,000,000-5,000,00$ & 15 \\
\hline & More than $5,000,00$ & 15 \\
\hline Favorite & Lifestyle products review & 48 \\
\hline $\begin{array}{l}\text { YouTube Con- } \\
\text { tent }\end{array}$ & $\begin{array}{l}\text { Culinary (food \& beverage) re- } \\
\text { view }\end{array}$ & 52 \\
\hline
\end{tabular}

The measurement model is assessed using reliability and validity. The validity test is done by looking at the Average Variance Extracted (AVE) value.

\begin{tabular}{llll}
\multicolumn{4}{c}{ Table 2. Construct's Reliability and Validity } \\
\hline $\begin{array}{l}\text { Con- } \\
\text { struct }\end{array}$ & $\begin{array}{l}\text { Cronbac } \\
\text { h's Al- } \\
\text { pha } \\
\text { (CA) }\end{array}$ & $\begin{array}{l}\text { Composite } \\
\text { Reliabil- } \\
\text { ity(CR) }\end{array}$ & $\begin{array}{l}\text { Average } \\
\text { Variance } \\
\text { Extracted } \\
\text { (AVE) }\end{array}$ \\
\hline AHSA & 0.769 & 0.815 & 0.690 \\
PA & 1.000 & 1.000 & 1.000 \\
PSI & 0.741 & 0.810 & 0.682 \\
BA & 1.000 & 1.000 & 1.000 \\
BIF & 0.807 & 0.912 & 0.838 \\
BV & 0.749 & 0.810 & 0.587 \\
BPI & 0.756 & 0.816 & 0.690 \\
\hline
\end{tabular}

According to Table 2, Cronbach's Alpha value for all constructs is above 0.6 and the composite reliability value for all constructs is above 0.7 , which indicates that all the constructs in the estimated model meet the criteria. AVE values of all constructs are above 0.5 for all constructs in the research model. The lowest value of AVE is 0.587 in the construct of brand value.
Table 3. Results of Hypotheses Testing

\begin{tabular}{llll}
\hline Hypothesis & $\begin{array}{l}\text { T } \\
\text { Stats* }\end{array}$ & $\begin{array}{l}\text { P Val- } \\
\text { ues** }\end{array}$ & Results \\
\hline $\begin{array}{l}\text { H1:AHSA } \rightarrow \\
\text { PSI }\end{array}$ & 5.994 & 0.000 & Supported \\
H2: PA $\rightarrow$ PSI & 2.393 & 0.017 & Supported \\
H3: PSI $\rightarrow$ BA & 0.773 & 0.440 & $\begin{array}{l}\text { Not Support- } \\
\text { ed }\end{array}$ \\
H4: PSI $\rightarrow$ BIF & 2.401 & 0.017 & Supported \\
H5: PSI $\rightarrow$ BV & 4.093 & 0.000 & Supported \\
H6a: BA $\rightarrow$ BPI & 1.464 & 0.144 & Not Support- \\
& & & ed \\
H6b: BIF $\rightarrow$ BPI & 2.824 & 0.005 & Supported \\
H6c: BV $\rightarrow$ BPI & 6.036 & 0.000 & supported
\end{tabular}

*T Statistics $>1.96$

$* * \mathrm{P}$ Values $\leq 0.05$

Table 3 shows that the relationship between AHSA, PA and PSI is supported by the T-statistic value $>1.96$ and $\mathrm{P}$ value $\leq 0.05$. The original sample estimate value that is owned is also positive, which indicates that the direction of the relationship between $\mathrm{AH}$ SA, PA and PSI is positive. Thus hypotheses 1 and 2 in this study which state that AHSA has a positive influence on PSI and PA has a positive influence on PSI are accepted. The relationship between PSI, BIF, and BV is supported. Hypotheses 4 and 5 in this study which state that PSI has a positive influence on BIF and PSI has a positive influence on BV are accepted. Meanwhile, the results of $\mathrm{H} 3$ testing indicate that PSI has no positive influence on BA, so hypothesis 3 is not supported. Hypotheses results between BIF, BV and BPI are supported. Hypotheses $6 \mathrm{~b}$ and $6 \mathrm{c}$, which state that BIF has a positive influence on BPI and BV has a positive influence on BPI, are accepted. However, hypothesis 6a is not supported, so that BA has no positive influence on BPI. Based on the hypothesis testing results, the relationship of each variable is found. The hypothesis in this study has implications, each of which has implications for the role of YouTubers on Covid-19 prevention products' purchase intention. 


\subsection{Attitude homophily and social attractiveness have a positive influence on PSI}

The results indicate attitude homophily and social attractiveness have a strong influence on PSI. This result is in accordance with the results of research by Lee \& Watkins (2016), Frederick (2012). Ballantine \& Martin (2005) state that the more a media user perceives the media personality to be similar to themselves and others in their interpersonal network, the more likely PSI would occur. The more attractive the media personality, the more likely the viewer think they have similar beliefs and lead them to attitude homophily. From millennial perceptions, YouTube personality that has a lot in common with the viewer is an example of how to think, values, and behavior make them feel more attached to the YouTubers. When YouTubers are able to share good messages through their vlog with like-minded viewers, they will interact more often.

\subsection{Physical attractiveness has a positive influence on PSI}

This hypothesis result shows that the physical appearance of the media personality can improve the communication relationship with the media users. This result is also supported by previous research by Lee \& Watkins (2016). According to Khamis \& Munt (2010), bloggers who use social media as a platform to establish their self-brands enjoy high levels of creativity and self-expression. YouTube viewers - especially millennials, like YouTubers whom are not only physically attractive but fun and do not get bored when watching. Millennials perceive that YouTubers who look fun to watch will make them feel comfortable watching their content. Viewers will be interested in interacting with their favorite YouTubers through the comment's column.

\subsection{PSI has no positive influence on brand awareness}

Brands can effectively enhance robust relationships with customers. Media amplifies the existing customer-to-firm and firm-to- customer relationships and presents new transformation on conventional options, boosting the ability of firms to interact with customer dialog and accordingly strengthening their communication tools (Tsimonis \& Dimitriadis 2014). In this study, there is no relationship between PSI and brand awareness. The social interactions shown by YouTubers in their channels do not increase millennial awareness of the Covid-19 prevention product brands. Millennials perceive that they are aware of Covid-19 prevention products such as masks, hand sanitizers, vitamins, healthy food, and others through YouTube Advertising (YouTube Ads). The PSI shown by YouTubers through product reviews is less influential than YouTube Ads.

\subsection{PSI has a positive influence on the brand- user-imagery fit}

High PSI with a vlogger increases positive brand-user-imagery fit. This is in line with Lee \& Watkins (2016) that reveal users tend to like what their idol vloggers like. Users would prefer similar brands with their favorite vlogger. Millennials tend to see which brand their favorite YouTubers are using. YouTubers' image usually also has an influence on the brand image of the Covid-19 prevention products. YouTubers will interact and influence viewers with images that match the product brand.

\subsection{PSI has a positive influence on brand value}

The results of this hypothesis also support previous research which states that PSI has a positive effect on brand value. Good social interaction will also improve the delivery of good brand values to customers. Good social interaction shown by YouTubers through YouTube vlogs will increase the brand value that the company wants to convey to its customers. Brand value of Covid-19 prevention products usually shown by good value for the money, good buy, and worthiness because the products' benefits outweigh the costs and value for the money than other brands. 
3.6 Brand awareness has no positive influence on brand purchase intention. Branduser-imagery fit and brand value has a positive influence on brand purchase intention

Dehghani et al. (2016) conclude that brand awareness through YouTube positively affects consumers' purchase intention, especially young customers. Firms usually use YouTube videos as part of their promotional strategy to increase brand awareness. However, this research concludes that there is no positive relationship between brand awareness and purchase intention. Millennials consider YouTube content as a medium to entertain them, relieve stress, and have fun. In millennial perceptions, brand awareness through YouTube Ads may be more influential than just through YouTubers' reviews.

The results of this study support previous research by Lee \& Watkins (2016) that stipulate PSI with vloggers increase positive brand perceptions of brand-user-imagery fit, brand value followed by purchase intentions. Vlogs are suitable media to influence viewers on purchase intention.

Millennials would buy and wear masks, hand sanitizers, soap, wet \& dry wipes, and other health \& hygiene equipment that are similar or the same or as recommended by their favorite YouTubers. They will first search for information through their favorite YouTube channel or YouTuber. They will also buy the same healthy foods and drink multivitamins as recommended by their favorite YouTubers. Millennials' willingness to buy certain products or brands will be high if they are widely reviewed on YouTube. Millennials' purchase intention to follow any recommendations related to the new normal would be high if their favorite YouTuber reviewed it. Socialization, information and education related to the new normal would be more easily understood and fun when delivered by their favorite YouTubers.

\section{CONCLUSION}

This study aims to investigate the role of YouTubers according to millennial percep- tions and their influence on purchase intention on the Covid-19 prevention products brand. Analysis in this study covers the use of vlog content by YouTubers and the relationship with viewers. Vlog content created and posted in a Covid-19 prevention product review represents the brand image and value.

This study investigates the relationship between viewers and vloggers and the subsequent influence of these perceptions on the Covid-19 prevention product brands and millennials' purchase intention. Overall, the results of this study support PSI as a brand management tool, except for brand awareness because the use of YouTube ads is more effective than a review by YouTubers for only first-time brand recognition. Through the submission of brand-user imagery fit and brand value, YouTubers have a positive influence on millennial purchase intention on Covid-19 prevention products.

From the managerial perspective, this research is precious for companies that invest in YouTubers as influencers or brand ambassadors as a marketing strategy. Companies that use YouTubers as part of their promotional strategy must always think about the entertainment suitable for their desired target market. Companies need to choose a YouTuber who reflects the brand image of their products and has the same value as the brand to be reviewed to enhance purchase intention for millennial consumers. In a pandemic era where all activities are predominantly online, companies must think cleverly to choose the right YouTuber for effective marketing strategies. From the government's perspective, socialization and policies in the new normal era will also be conveyed more quickly to the millennial generation through the right YouTuber. Millennial viewers tend to follow YouTubers as their role models so that information can be delivered more quickly and accurately.

Finally, some of the limitations of this study must be considered. First, in this study, the sample size could not fully represent the entire population of YouTube viewers. Further research is needed using various samples that include other segments than millennials. Second, the object in this study 
also does not limit one particular product because the initial objective is to assess the effectiveness of companies that market Covid19 prevention products through YouTubers in the new normal era. Future research can use one particular object with a variety of brands.

\section{REFERENCES}

Ballantine, P.W. \& Martin, B.A.S. 2005. Forming ParaSocial Relationships in Online Communities. Advances in Consumer Research 32(83): 197-201.

Bian, Q. \& Forsythe, S. 2012. Purchase Intention for Luxury Brands: A Cross Cultural Comparison. Journal of Business Research 65(10): 1443-1451.

Dehghani, M., Niaki, M.K., Ramezani, I. \& Sali, R. 2016. Evaluating the Influence of YouTube Advertising for Attraction of Young Customers. Computers in Human Behavior 59: 165-172.

Eyal, K. \& Rubin, A.M. 2003. Viewer Aggression and Homophily, Identification, and Parasocial Relationships with Television Characters. Journal of Broadcasting \& Electronic Media 47(1): 77-98.

Frederick, E.L., Lim, C H., Clavio, G. \& Walsh, P. 2012. Why We Follow: An Examination of ParaSocial Interaction and Fan Motivations for Following Athlete Archetypes on Twitter. International Journal of Sport Communication 5(4): 481-502.

Freeman, B. \& Chapman, S. 2007. Is "YouTube" Telling or Selling You Something? Tobacco Content on the YouTube Video-Sharing Website. Tobacco Control 16(3): 207-210.

Khamis, S. \& Munt, A. 2010. The Three Cs of fashion media today: Convergence, creativity and control. SCAN Journal of Media Arts Culture 8(2):1-13.

Kim, A. J. \& Ko, E. 2012. Do Social Media Marketing Activities Enhance Customer Equity? An Empirical Study of Luxury Fashion Brand. Journal of Business Research 65(10): 1480-1486.

Labrecque, L.I. 2014. Fostering Consumer-brand Relationships in Social Media Environments: The Role of Para-social Interaction. Journal of Interactive Marketing 28(2): 134-148.

Lee, E.J. \& Watkins, B. 2016. YouTube Vloggers' Influence on Consumer Luxury Brand Perceptions and Intentions. Journal of Business Research 69(12): 5753-5760.

Miller, K.W. \& Mills, M.K. 2012. Contributing Clarity by Examining Brand Luxury in The Fashion Market. Journal of Business Research, 65(10): 14711479.

Stephen, A.T. \& Toubia, O. 2010. Deriving Value from Social Commerce Networks. Journal of Marketing Research 47(2): 215-228.

Stever, G. S \& Lawson, K. 2013. Twitter as a Way for Celebrities to Communicate with Fans: Implications for The Study of Para-social Interaction. North American Journal of Psychology 15(2): 339-354.

Tsimonis, G. \& Dimitriadis, S. 2014. Brand Strategies in Social Media. Marketing Intelligence \& Planning 32(3): 328-344.

Zhang, B. \& Kim, J. H. 2013. Luxury Fashion Consumption in China: Factors Affecting Attitude and Purchase Intent. Journal of Retailing and Consumer Services 20(1): 68-79. 